\title{
Levantamento de tendências em gestão do conhecimento no Brasil: análise de conteúdo da opinião de especialistas brasileiros
}

Jaqueline Santos Barradas

Oficial da Força Aérea Brasileira. Membro do Corpo Permanente da Escola Superior de Guerra e Mestre em Administração (IBMEC)

Luiz Alberto Nascimento Campos Filho

Professor Adjunto III das Faculdades

Ibmec RJ. Estágio pós-doutoral em Estratégia (INSEAD). Doutor em Engenharia de Produção (USP)

O objetivo do presente artigo é apresentar o levantamento de tendências em gestão do conhecimento no Brasil. Para tanto, foram realizadas 30 entrevistas com especialistas da área, tratadas por meio de análise de conteúdo. Como resultado, verificou-se a existência de duas abordagens distintas: uma por temas mais consolidados (disseminação do tema, barreiras e dificuldades, medição de resultados e modismo) e, outra, por temas menos consolidados (terminologia, avanços práticos e teóricos e tendências). Conclui-se que ainda não há consenso nas respostas relativas às tendências.

Palavras-chave: Gestão do conhecimento; Gestão da informação; Tendências.

\section{Knowledge management trends in Brazil content analysis in the opinion of brazilians' specialists}

This article regards Knowledge Management (KM) trends in Brazil. Thirty interviews were conducted with specialists and treated with content analysis approach. The analyses of the results detected two distinct approaches. The first 
approach was considered more consistent with the following subjects: topic dissemination, its ephemeral characteristic, difficulties, and measurement of results. In the second approach, less consistent issues were involved (terminology issue, the development of theory and practice, and trends). As a conclusion, there wasn't a consensus regarding answers about $K M$ tendencies.

Keywords: Knowledge Management; Information Management; Trends.

\section{Recebido em Aceito 18.10.2010}

\section{Introdução}

O conhecimento e sua utilização não são elementos novos, uma vez que sempre acompanharam a atividade do ser humano (DAVENPORT; PRUSAK, 1998). No entanto, em face da expansão global dos mercados e da competitiva economia baseada em conhecimento, onde o futuro será essencialmente determinado pela nossa habilidade em usá-lo sabiamente, "[...] as organizações estão rapidamente procurando formas de gerenciar o imenso potencial que seus ativos do conhecimento podem proporcionar, rumo à era de inovação" (SHARIQ, 1997, p. 75, tradução nossa)

Corroborando as afirmações acima, Toffler e Toffler (2007, p. 10), em seu último lançamento literário - A Riqueza Revolucionária, afirmam que "[...] à medida que a globalização permite que se compartilhe toda e qualquer informação em tempo real, em todas as partes do mundo, a importância do conhecimento para a criação de riquezas é cada dia maior e está prestes a atingir um nível ainda mais relevante".

Considerando 0 valor econômico que o conhecimento vem conquistando, autores, como Teixeira Filho (2000, p. 22), definem a gestão do conhecimento (GC) "[...] como uma coleção de processos que governa a criação, a disseminação e a utilização do conhecimento para atingir plenamente os objetivos da organização $[\ldots]^{\prime \prime}$, que reconheça o conhecimento como seu principal recurso.

O artigo tem como objetivo levantar tendências da gestão do conhecimento (GC) no Brasil, considerando os conceitos estabelecidos na literatura nacional e internacional, a disseminação do tema junto aos especialistas brasileiros, os avanços práticos e teóricos recentes, as barreiras e dificuldades que permeiam as ações de implantação da GC, as avaliações e medições de resultados e o questionamento quanto a ser 0 assunto um modismo ou não. 
Aponta os caminhos por onde a disciplina poderá fluir, possibilitando aos gestores públicos e privados, que utilizam ou pretendam utilizar a GC para conduzir suas organizações, tomar decisões mais coerentes e corretas, optar por soluções em consonância com as suas necessidades específicas, tendo como balizadoras as considerações indicadas neste estudo.

Para alcançar os objetivos propostos utilizou-se uma metodologia de pesquisa apresentada em duas fases distintas. Na primeira fase, houve um mapeamento da literatura nacional e internacional e, na segunda fase, a realização de 30 entrevistas com especialistas em GC no Brasil, tratadas por meio de análise de conteúdo.

Esta pesquisa pretende contribuir com a divulgação da temática sobre gestão do conhecimento, com o que de mais relevante está sendo divulgado pela literatura dos periódicos nacionais e internacionais e 0 pensamento dos especialistas atuantes no Brasil, expondo semelhanças e diferenças, pontos comuns e incomuns, evidências e descobertas.

\section{Referencial Teórico}

Segundo An Illustrated Guide of KM (s.d.), a gestão do conhecimento é um rótulo para o entendimento do conhecimento como fator de produção e gerenciamento do ambiente organizacional, a fim de dar suporte à transferência do conhecimento individual e à consequente criação do conhecimento coletivo, dois essenciais fatores no processo de criação de valor. A GC não seria gestão do conhecimento como um fim em si mesmo, mas o gerenciamento da organização com foco no conhecimento.

A difusão da GC se deu a partir do clássico "Criação do Conhecimento na Empresa", de Nonaka e Takeuchi (1997). O modelo de criação do conhecimento foi recebido pela comunidade acadêmica como um marco no campo da Ciência da Informação (HENRIQUE; BARBOSA, 2005). Outros modelos reconhecidos foram difundidos por autores clássicos da área, como T. Davenport e L. Prusak (1998), Karl-Erik Sveiby (2001) e Thomas Stewart (1998).

Mais adiante, surgem outras abordagens da GC, denominadas de segunda geração: Dave Snowden (2002), que definiu o conceito de divisão da GC em três eras e Firestone e McElroy (2003), que abordaram a Nova Gestão do Conhecimento.

Em relação às eras, a primeira referia-se a um período anterior a 1995, e tinha como foco a informação em tempo hábil para a tomada de decisão, ênfase em iniciativas de reengenharia, automação da gestão e do binômio tecnologia/eficiência (SNOWDEN, 2002).

A segunda era, situada entre 1995 e 2002, baseou-se na popularização do modelo de Nonaka e Takeuchi e inseriu uma crítica ao dualismo na concepção de conhecimento tácito e explícito, em detrimento de uma visão dialética (CAMPOS, 2007).

A terceira era, ainda por vir, seria caracterizada pela visão paradoxal do conhecimento como coisa e fluxo, requerendo diversas abordagens gerenciais. Preconiza como ferramentas, técnicas antropológicas para 
desvelar o conhecimento; histórias como forma avançada de repositório de conhecimento e modelo just-in-time de GC, que gerencia tanto o conhecimento quanto os canais por onde ele flui entre comunidades formais e informais. Caracteriza-se, ainda, pela centralidade dos conceitos de gestão de contexto, de narrativa e de conteúdo, pelo entendimento da organização como um sistema adaptativo complexo e pelo questionamento da ortodoxia da administração científica (ARAÚJO, 2006; CAMPOS, 2007; SNOWDEN, 2003).

Em 2001, surgiu a abordagem da Nova Gestão do Conhecimento (NGC), desenvolvida por Firestone e McElroy (2003), consultores e sócios fundadores do Consórcio Internacional de Gestão do Conhecimento, com base no trabalho inicial de McElroy (1999). Eles acreditavam nessa nova perspectiva para responder às questões atuais, até então não atendidas, e nas perspectivas futuras da GC que estavam paralisadas na visão anterior.

Trata-se de uma designação para o conjunto de temas, práticas e modelos que enfatizam a integração do conhecimento (compartilhamento, divulgação, recuperação e ensino), assim como sua produção e geração (CAMPOS, 2007). O modelo pretende ser integrativo e de amplo escopo, abrangendo tópicos afins, como estratégia e cultura organizacionais, redes sociais, melhores práticas, capital intelectual, tecnologia e criação de sentido (CAMPOS, 2007).

Entretanto, o que se propõe como NGC deve ser avaliado para se verificar até que ponto carrega, de fato, uma novidade na área. O que se apresenta como novo, mesmo após cinco anos do seu lançamento (2002/2003), é ainda desconhecido por grande parte dos autores da área.

Algumas questões devem ser destacadas, nesse referencial, por terem sido citadas ao longo das entrevistas, tais como a origem da GC nos campos da Ciência da Informação e na Administração; a discussão terminológica e conceitual acerca da gestão da informação e da gestão do conhecimento; os modelos de maturidade em GC e alguns marcos representativos da GC na sociedade brasileira.

Sobre a origem da GC e seus campos de discussão, Davenport e Cronin (2000 apud HENRIQUE; BARBOSA, 2005) propõem que a GC seja explorada a partir de três domínios: Biblioteconomia e Ciência da Informação, engenharia de processos e teoria organizacional. No primeiro domínio, a GC é predominantemente vista como gestão da informação. No segundo domínio, na engenharia de processos, a GC deve ser vista como gestão de know-how, com ênfase em processos e atividades e frequentemente igualada à tecnologia da informação. No terceiro domínio, - da teoria organizacional, denota uma mudança conceitual maior, destacando a GC como um recurso, responsável pela criação de contextos e espaços onde os conhecimentos tácitos e explícitos de todos os membros da organização interagem, proporcionando maior efetividade à ação organizacional.

Autores como Scholl et al. (2004), declaram que GC é um campo relativamente difuso e caracterizado por diferentes conceitos, perspectivas e abordagens. Dizem, ainda, que a GC expande-se em múltiplas áreas e 
afirmam que existe um patchwork de subdomínios em volta da GC, que trata de um conjunto de temas enquanto ignoram outros.

A essas afirmações somam-se outras discussões, terminológicas e conceituais acerca da GC. Alvarenga Neto, Barbosa e Pereira (2007, p. 7) defendem que "[...] a GC alimenta-se da indefinição e de toda a controvérsia sobre os conceitos e linhas divisórias entre dados, informação, conhecimento e sabedoria [...]". Para Wilson (2006, p. 37), "não existe um núcleo comum na literatura de $\mathrm{GC}^{\prime}$ e a mesma "[...] encontra-se dispersa em grande diversidade de áreas, desde a inteligência artificial, passando por aplicações de tecnologia informacional, até o desenvolvimento organizacional". Esse mesmo autor observa, ainda, "[...] que o desenvolvimento da literatura básica da área não corresponde às expectativas" (WILSON, 2006, p. 52). Para Kay (s.d., tradução nossa), dada a ambiguidade e confusão que ronda o termo, a ausência de um rótulo para a GC pode ser um fator positivo.

Souza, Alvarenga Neto e Mendes (2007, p. 20) também dissertam sobre esse tema e afirmam que, "[...] embora muita atenção acadêmica e profissional tenha sido devotada à GC na última década, o conceito ainda não é estável." Esses autores ratificam a importância de estudos na área e dizem que ao se aceitar a afirmação de não existência da temática da GC, perde-se a oportunidade de aprofundamentos em temáticas pertinentes à área.

Quanto à questão da gestão da informação (GI), Alvarenga Neto, Barbosa e Pereira (2007) consideram-na ponto de partida para a implementação de programas de GC, uma vez que norteia e valida amplamente outras atividades e temas vinculados à GC, como a gestão do capital intelectual, a aprendizagem organizacional dentre outros. Em estudo realizado com três empresas que implantaram programas de GC, os autores acima aludidos citam que os entrevistados foram inquiridos sobre aspectos prioritários acerca da GC em suas organizações, e que se observou que a GI é o ponto de partida para quaisquer iniciativas de GC.

Ressaltando uma tendência importante na consolidação da área, cabe destacar o tema modelos de maturidade em GC citados nas entrevistas, como o CMM (Capability Maturity Model), o Knowledge Management Maturity Model (KMMM), o Modelo OKA e o prêmio MAKE.

Paulk et al. (1995 apud CARVALHO; FERREIRA; KILIMNIK, 2007) revelam que os modelos de maturidade de GC recebem inspirações principalmente dos modelos de controle de qualidade e do modelo Capability Maturity Model (CMM), de maturidade do desenvolvimento de software, proposto pelo Software Engeneering Institute, da University Carnegie Mellon - EUA (SEI). O CMM focaliza os processos, considerandoos como fator de produção com maior potencial de produção em curto prazo. Outros fatores, como tecnologia e pessoas, só são tratados pelo CMM na medida em que interagem com as pessoas (GOLDMAN, 2008).

O Knowledge Management Maturity Model (KMMM), um dos modelos de maturidade em GC, localizado na literatura e utilizado como instrumento interno da empresa Siemens, adapta o conceito de 
maturidade para o domínio da GC e adota as mesmas classes do CMM para identificar seus cinco níveis: inicial, repetitivo, definido, gerenciado e otimizado (BRUNO, 2008).

Além do KMMM, existe outro modelo de maturidade em GC, o modelo Organizational Knowledge Assessment Methodology (OKA), do Banco Mundial. O objetivo do OKA é proporcionar uma forma de coletar, mensurar e estudar a GC em uma organização. É um mecanismo que permite que as organizações compreendam seus níveis de aptidão e capacidade em GC, identificando as áreas-chave que precisam ser desenvolvidas e aprimoradas. Desta forma, compreendendo suas forças e fraquezas, as empresas podem focar suas atividades de gestão do conhecimento de forma a diferenciá-las no mercado. Esse modelo é uma ferramenta que capacita os tomadores de decisão a melhor compreender e justificar seus investimentos em GC, bem como contribuir com uma estrutura e linguagem padrão sobre GC na organização e, ainda, serve como uma estrutura valiosa para compreender a natureza da GC e seus impactos na organização.

Ainda se tratando de modelos de maturidade, cabe destacar o prêmio Most Admired Knowledge Entreprise (MAKE), que se propõe a avaliar e certificar as empresas que se destacarem em projetos que valorizem o conhecimento como fator que promova a inovação, contribua para a criação de ambiente para compartilhamento e que permita a colaboração e a gestão do capital intelectual e da aprendizagem organizacional, bem como focalizar o conhecimento do cliente e a valorização da organização para seus acionistas. As empresas candidatas são avaliadas por meio de diretrizes, que constituem os oito critérios do Prêmio MAKE. A cada empresa candidata ao prêmio é enviado um relatório com um sistematizado feedback, que irá sinalizar pontos em que a instituição poderá aperfeiçoar seus processos para buscar a excelência em GC (SIMÃO, 2008).

No que diz respeito aos marcos representativos da sociedade brasileira, é importante comentar sobre a proposição de uma política de GC para a Administração Pública Federal (PGC/APF), indicada por um estudo do IPEA em 2005 (FRESNEDA, 2007), elaborada por um Comitê Técnico de Gestão do Conhecimento e Informação Estratégica (CT-CGIE) e encaminhada ao Congresso Nacional em dezembro de 2007. A proposta, oriunda de um trabalho colaborativo coletivo, vem sendo desenvolvida desde outubro de 2003, quando da publicação de um Decreto que criou oito comitês técnicos, inclusive o CT-CGIE. Conta com a efetiva participação e apoio de atores e órgãos expressivos no cenário público federal, como o SERPRO, a EMBRAPA, o Ministério da Agricultura, dentre outros.

Outro marco importante, citado durante as entrevistas e que merece ser divulgado, é a adoção de parâmetros baseados em ativos intangíveis utilizados pelos BNDES para a avaliação de projetos de implementação de empresas nascentes de base inovadora (FINGERL, 2007). O que hoje se vê é a utilização de métricas e metodologias do passado para se avaliar 
empresas que têm nos ativos intangíveis a sua essência, criação e manutenção de valor. Com essa ação, o BNDES muda um paradigma estabelecido, altera a política para a concessão de recursos financeiros às empresas e os parâmetros para a condução e avaliação de empresas em nível nacional, fazendo com que as organizações mudem para se adaptar.

A próxima parte apresenta a metodologia utilizada para o desenvolvimento da pesquisa.

\section{Metodologia}

Tendo em vista que o objetivo da pesquisa - identificar tendências da GC no Brasil - apóia-se na opinião de especialistas da área, o método qualitativo mostrou-se o mais adequado para a realização do levantamento. Segundo Minayo, "o método qualitativo é o que se aplica ao estudo da história, das relações, das representações, das crenças, das percepções e das opiniões, produto das interpretações que os humanos fazem a respeito de como vivem, constroem seus artefatos e a si mesmos..." (MINAYO, 2006, p. 57).

Para a coleta de dados escolheu-se a entrevista semiestruturada. Segundo Minayo (2006), as entrevistas podem ser consideradas conversas com finalidade e se caracterizam pela sua forma de organização.

A amostragem, para a presente pesquisa, constitui-se de um conjunto de 30 especialistas com representação e ou atuação em diferentes segmentos da sociedade: universidades, governo, indústria, terceiro setor, consultoria e outros. Alguns dos entrevistados foram identificados, a partir de uma pesquisa em que Barradas e Campos Filho (2008), citaram autores mais prolíficos, em cada área.

O questionário dividiu-se em dois blocos. O primeiro bloco procurava identificar e qualificar o entrevistado, para traçar um perfil do mesmo e, na compilação final das entrevistas, traçar um perfil do grupo de entrevistados. O segundo bloco continha oito perguntas abertas, com o objetivo de identificar as ideias e experiências dos entrevistados com os temas em questão.

As entrevistas foram gravadas em arquivos digitais, com prévia autorização dos entrevistados e resultaram em 28 horas de gravação, em média de 56 minutos cada. As transcrições das entrevistas geraram 110 páginas digitadas, em média de 3,7 páginas por entrevista. Os resultados foram tratados pergunta a pergunta, originando 240 respostas.

Após realizadas todas as entrevistas, passou-se à análise e interpretação das mesmas, por meio do método de análise de conteúdo, tratado na seção a seguir.

\subsection{Análise de conteúdo}

Dentre os métodos existentes para análise e interpretação dos dados de uma pesquisa qualitativa, o método de análise de conteúdo mostrou-se o mais adequado, por se aplicar a discursos extremamente 
diversificados (BARDIN, 2004). Por isso, foi o método escolhido para tratar as entrevistas da presente pesquisa.

A análise de conteúdo consiste em um conjunto de técnicas de análise das comunicações (BARDIN, 2004). Dentre as técnicas de análise de conteúdo anunciadas por Bardin (2004), podem-se enumerar as análises categorial, de avaliação, de enunciação, da expressão, das relações e do discurso. Para aplicação, na presente pesquisa, optou-se pela técnica de análise categorial ou temática, por ser a mais simples de se aplicar.

Segundo Bardin (2004), análise categorial ou temática pode ser definida como "o método das categorias, espécie de gavetas ou rubricas, significativas, que permitem a classificação dos elementos de significação constitutivos da mensagem (BARDIN, 2004, p. 32). O método consiste nas operações de divisão de texto em unidades, em categorias, segundo reagrupamentos analógicos.

Para o tratamento das informações, foram considerados 2 blocos em que se dividiram os questionários. As respostas referentes ao bloco 1qualificação dos entrevistados - foram agrupadas segundo categorias previamente estabelecidas e tratadas com percentagens, em uma planilha do software Excel.

No que se refere ao bloco 2, as respostas foram tratadas pergunta a pergunta. Primeiro foram tratadas todas as respostas da pergunta 1 , depois da pergunta 2 e, assim, sucessivamente, até a pergunta 8 . Dessas respostas, destacaram-se os núcleos de sentido de cada oração, desprezando o que não fosse pertinente à pergunta, como comentários explicativos desnecessários ou evasivos.

Em seguida, essas respostas foram agrupadas por categorias previamente estabelecidas, segundo as regras de homogeneidade, exaustividade, exclusividade, objetividade e adequação (BARDIN, 2004). As categorias foram nominadas com títulos representativos do contexto analisado e representadas através de percentagens.

A próxima seção apresenta os resultados das entrevistas.

\section{Resultados das entrevistas}

Esta seção apresenta a caracterização da amostra da pesquisa e as análises das respostas. Trata as oito perguntas constantes do questionário aplicado e define as categorias para cada grupo de respostas, de acordo com a metodologia de análise de conteúdo, detalhada na seção anterior.

\subsection{Caracterização da amostra}

Ao todo, foram entrevistados 30 especialistas, 19 (63\%) do sexo masculino e 11 (37\%) do sexo feminino. Todas as informações tratadas nessa seção foram prestadas pelos próprios entrevistados, coletadas durante as entrevistas. A formação acadêmica dos entrevistados demonstra o alto nível de escolaridade: 27 \% com especialização, 33\% 
com mestrado e $40 \%$ com doutorado. Nenhum dos entrevistados possuía somente graduação superior.

Os entrevistados informaram trabalhar com gestão do conhecimento entre 3 e 39 anos. A média da amostra ficou em torno de 10,5 anos. Destes, 40\% encontram-se com até 7 anos de experiência, 43\% entre 8 e 14 anos de experiência e 17\% com mais de 15 anos de experiência.

As funções ocupadas pelos entrevistados foram segmentadas em 4 grupos. O grupo 1 (gestor, coordenador e diretor) continha $70 \%$ da amostra, com 21 entrevistados. O grupo 2 (professor e tutor) 13\%, com 4 entrevistados. O grupo 3 (estudante e pesquisador) $7 \%$, com 2 entrevistados e o grupo 4 (consultor e outros) 10\%, com 3 entrevistados. Muitos entrevistados informaram acumular funções em suas organizações com a prática acadêmica e, ainda, em organizações do terceiro setor. Para efeitos desta pesquisa, considerou-se apenas a principal função exercida.

A pesquisa procurou saber o segmento de mercado em que o entrevistado atua. Os segmentos foram agrupados em seis classes: universidades, governo, indústria, consultoria, terceiro setor e outros. Os segmentos mais presentes entre os entrevistados foram: governo e academia - com 33\% cada; indústria - com 20\%; consultoria - 10\%; e outros - com 3\%.

Sobre o nível de conhecimento sobre GC, os entrevistados responderam em uma das cinco gradações: não conheço, conheço pouco, conheço mais ou menos, conheço bem e conheço profundamente. Assim, $17 \%$ informaram conhecer mais ou menos; $30 \%$ bem; e $53 \%$ afirmaram conhecer profundamente. Nenhum dos entrevistados se enquadrou nas categorias não conheço ou conheço pouco. Esses $17 \%$ que afirmam conhecer mais ou menos a GC tiveram suas respostas descartadas, para fins de análise de tendências.

Os entrevistados são oriundos das cidades do Rio de Janeiro, Belo Horizonte, São Paulo, Brasília e Porto Alegre.

\subsection{Apresentação e análise dos resultados}

Esta seção representa um momento de síntese, em que são comparadas as perguntas respondidas com o que foi efetivamente encontrado sobre os temas na literatura nacional e internacional. Tem como objetivo dar uma consistência às considerações da pesquisa, buscando-se afirmações que ratifiquem ou refutem as opiniões dos entrevistados ou mesmo apontem direções diferentes.

Verificou-se a existência de duas abordagens distintas dos temas considerados no objetivo da presente pesquisa. Uma por temas mais consolidados na literatura e presentes nos resultados desta pesquisa e outra por temas menos consolidados, em discussão efervescente. 


\subsubsection{Temas mais consolidados}

Nos resultados desta pesquisa estão os que se organizaram em até quatro categorias ou com concentração maior que $50 \%$, em uma das categorias, como é o caso das barreiras e dificuldades. São eles: disseminação do tema, barreiras e dificuldades, medição de resultados e modismo.

\subsubsection{Disseminação do tema}

A pergunta 2 - O que você acha sobre a disseminação do assunto GC nas empresas em geral, na literatura, no domínio de conhecimento das pessoas que atuam na empresa? - teve como objetivo identificar a percepção dos entrevistados sobre a disseminação do assunto.

As respostas foram agrupadas em quatro categorias: o tema é conhecido, o tema não é conhecido, o tema é confundido e o tema é desvirtuado. Dessa forma, $40 \%$ dos entrevistados afirmaram que o tema é conhecido, embora outros $30 \%$ afirmaram que o tema não é conhecido. Outros $17 \%$ afirmam que o tema é desvirtuado e $13 \%$ que o tema é confundido.

Sobre a categoria "o tema é conhecido", alguns entrevistados alertam para o fato que os periódicos de grande circulação, os chamados pop-management, é que ajudam a popularizar, divulgar e promovem o tema GC. Afirmam, ainda, que, na literatura e na academia, o tema é bem conhecido e nas empresas, em geral, começa a ganhar corpo.

$\mathrm{Na}$ categoria "o tema não é conhecido", os entrevistados afirmam que a GC ainda é muito embrionária, muito distante da realidade dos gerentes e que, na realidade, a maior parte dos executivos do setor de alto nível desconhece a GC. Ela faz parte de um processo de educação muito novo.

Na categoria "o tema é confundido", os entrevistados apontam que há uma confusão conceitual entre gestão da informação e GC. Há ainda banalização, em função da falsa crença de que as tecnologias podem resolver tudo. Na categoria "o tema é desvirtuado", apontam a má condução do tema na sociedade, que além de dificultar o pleno entendimento da disciplina, prejudica quem o faz corretamente.

$\mathrm{Na}$ questão envolvendo a disseminação do tema, grande parte dos entrevistados afirma que o tema GC é bem conhecido (40\%), relativamente difundido, que as empresas estão preocupadas com isto, embora não se trate de um tema de massa. Outra parte afirma que é um tema embrionário, fechado, apropriado por grupos dentro da academia (10\%). Portanto, verifica-se que há uma contradição entre os respondentes.

No tocante ao desconhecimento do tema, em pesquisa realizada pelo IPEA, em 2005, (FRESNEDA; GONÇALVES, 2007) sobre GC na esfera 
pública, foi detectado que não há, por parte dos servidores, um entendimento claro do que seja o conceito de GC ou de suas práticas e $64 \%$ dos respondentes afirmaram que GC é um conceito abstrato, discutido por pequenos grupos informais, embora reconheçam a necessidade dos órgãos públicos se prepararem para utilizar o conhecimento, em prol do coletivo.

Em relação à questão "o tema ser confundido", alguns entrevistados apontam que há uma confusão conceitual entre a gestão da informação e a GC. Para Wilson (2006), muitos autores continuam a usar os termos conhecimento e informação como sinônimos e parecem incapazes de entender a diferença entre ambas as áreas e seus recursos.

Ainda sobre esse tema, os resultados desta pesquisa acusam a forma equivocada como são tratadas as soluções tecnológicas, como solução utópica para os problemas da GC. Para gerentes menos atentos a essas questões, isto pode conduzir a uma decisão errada ou provocar retrocessos no processo de adoção da GC pelas organizações. Quanto à desvirtuação do tema, alguns entrevistados citam um fato que merece cuidado. Alertam para a proliferação de consultores oportunistas que se apropriam de rótulos e se lançam no mercado indevidamente, banalizando suas atuações e desprestigiando a área. Essas afirmações são ratificadas por Wilson (2006, p. 44,) quando cita que a GC tem sido "[...] promovida como solução utópica para os problemas organizacionais".

Com isso, pode-se afirmar que os resultados desta pesquisa estão consoantes e ratificados com o que a literatura aponta e que existem pontos de convergência entre eles. No entanto, questões relativas à disseminação da temática devem ser revistas e trabalhadas, com a adoção de futuras pesquisas que melhor esclareçam as contradições apontadas, visando a minimizar entendimentos equivocados sobre o tema.

\subsubsection{Barreiras e Dificuldades}

A pergunta 5 - Quais você considera as principais dificuldades/eventuais barreiras atuais na adoção da GC? - procurou identificar os problemas que afetam a adoção da GC, na opinião dos entrevistados.

As respostas foram agrupadas em seis categorias: "cultura"; "comprometimento da alta direção"; "intangibilidade do processo"; "falta de conhecimento sobre GC"; "educação formativa de base"; e "outros". Cultura representou $53,3 \%$ das respostas. Os $46,7 \%$ restantes, dividiram-se em cinco categorias. Comprometimento da alta direção e intangibilidade do processo apontaram $10 \%$ das respostas, cada uma. Falta de conhecimento sobre GC e educação formativa de base 6,7\% cada. A categoria "outros" destacou-se com 13,3 \% das respostas.

$\mathrm{Na}$ categoria "cultura" foram citados vários conceitos relacionados como liderança, cultura organizacional, cultura pública e mudança de paradigma. Importante ressaltar que $25 \%$ dos que apontaram cultura como barreiras também citaram outras das alternativas. 
Para Davenport e Prusak (1998, p. 172), a GC eficaz só poderá ocorrer com a ampla mudança comportamental, cultural e organizacional. Afirma ainda "[...] não existe uma tecnologia certa para GC. O elemento mais essencial é começar e que iniciativas ligadas ao conhecimento devem começar com um programa-piloto".

Comprometimento da alta direção refere-se ao apoio político e financeiro da cúpula da organização, que deve estar engajada e sensibilizada ao movimento. Envolve ainda, segundo os entrevistados, a análise da relação custo versus benefício do investimento, a definição clara dos objetivos e a priorização em face dos inúmeros motivos políticos, próprios das organizações.

A categoria "falta de conhecimento em GC" destaca o desconhecimento do tema - gerenciar conhecimento. A categoria "falta de conhecimento", aqui citada como dificuldade ou barreira para a adoção de GC, ratifica as respostas analisadas na pergunta anterior, sobre a disseminação do tema, sendo que 60 \% o desconhecem, o confundem ou o desvirtuam.

Em "educação formativa de base", os entrevistados afirmam que é necessária uma educação de base e liderança. Acrescentam que a formação pelo sistema educativo formal não contribui para as demandas necessárias para se viver na sociedade do conhecimento. O sistema acadêmico posto não ajuda, gerando fragmentação social na escola.

Embora cerca de $50 \%$ tenham defendido que a cultura organizacional seja a principal dificuldade/ barreira para a adoção da GC, é na categoria aqui definida como "outros" (13,3\%), que desperta interesses curiosos. É interessante abordar uma resposta que aponta para o fenômeno do imediatismo, próprio da cultura brasileira, que descarta projetos de longo prazo, inviabilizando a adoção de ações permanentes de GC nas organizações.

Ainda na categoria "outros", foi citado o fato de fazer GC sem previamente tratar a gestão da informação (GI). Não que esta seja, necessariamente, um pressuposto para que a outra ocorra, mas a sua existência facilita, abrevia processos e permite avançar mais rápido.

Diante dos resultados, que envolvem a questão das dificuldades e barreiras à adoção da GC nas organizações, é possível afirmar que as respostas das entrevistas tratadas, nesta pesquisa, estão coerentes e alinhadas com o que a literatura apresenta, o que demonstra haver um tema mais consolidado.

\subsubsection{Medição de resultados}

A pergunta 6 - Como você consegue medir os resultados práticos da GC no seu segmento de negócio? - teve como objetivo identificar métricas utilizadas em projetos de GC, aos quais os entrevistados estão inseridos. Foi a pergunta mais polêmica e que gerou um discurso longo por parte dos entrevistados, ricos em exemplos de aplicações variadas. 
Os resultados foram agrupados em três categorias: 70 \% afirmam que conseguem medir, $27 \%$ afirmam que não conseguem medir e apenas um não respondeu.

A categoria "consegue medir" apontou as medições qualitativas como a melhor maneira de medir resultados em projetos e ações de GC. Consideram os elementos subjetivos, de difícil mensuração direta. Muitos citaram os mapas de BSC (Balanced Scorecard) de Kaplan e Norton (1997) e KS Enabled, como exemplos de métrica de sucesso.

Embora os resultados da pesquisa tenham apontado que $70 \%$ conseguem medir, poucos, de fato, apresentaram métricas consistentes. Muitos citam que estão pensando em fazer e que é possível, porém nunca o fizeram. As exceções foram os casos comentados pelos entrevistados do BNDES, da Central Globo de Produções e da ELETRONUCLEAR, que demonstraram, através de resultados consistentes, a forma como conseguem medir suas práticas em GC.

Enquanto não for possível aferir, com fidedignidade, os resultados das ações de GC, com métricas por práticas, será muito difícil consolidar a área, uma vez que os empresários querem saber, de fato, o que vão ganhar com isso, quanto investir e quanto terão em retorno.

Alguns entrevistados apontaram formas diretas, bem objetivas, para medir resultados. A transformação do conhecimento em um produto palpável, como um sofwtare à venda na prateleira de uma loja, seria uma forma de materialização do conhecimento. Uma questão que ficou bem clara é que, embora existam diversas formas de medir os resultados da GC, não existe uma forma padrão a ser adotada. Os modelos de maturidade em GC ajudam a quantificar e a qualificar aplicações da GC nas organizações conferindo resultados palpáveis à administração.

Na categoria "não conseguem medir", os entrevistados alegaram que ainda não estão fazendo isso pela dificulade e intangibilidade do processo e, também, pelo desconhecimento de como fazê-lo efetivamente.

Pode-se concluir, a partir da análise das entrevistas e suas respostas, que os resultados desta pesquisa estão consoantes com o que a literatura aponta. Porém, existe uma lacuna de estudos nesta área específica da GC, que pode abrir espaço para linhas de pesquisa, na tentativa de avaliar, definir indicadores por práticas de retenção de conhecimento e por utilização de conhecimento.

\subsubsection{Modismo}

A pergunta 7 - Como você vê hoje a GC? Acha que a GC é um modismo ou evolução gerencial que veio para ficar? - teve como objetivo saber a opinião do entrevistado sobre o que representa hoje a GC e suas possíveis tendências.

Para essas respostas foram definidas três categorias. Uma unanimidade entre os entrevistados (93,3\%), equivalente a 28 respostas, afirmam que GC "não é modismo". Apenas duas respostas diferentes: 
uma na categoria "é modismo" e outra, na categoria "outros", ambas com $3,3 \%$.

Na categoria "não é modismo", muitos afirmam que a GC é um processo irreversível, que veio para ficar e que tende a se consolidar com o passar do tempo e com o amadurecimento das empresas. Outros a consideram uma evolução gerencial, uma prática de gestão.

A categoria "é modismo", embora representada por um resultado somente, aponta para um questionamento intrigante, uma vez que o respondente foi enfático ao afirmar que apenas $20 \%$ dos que a utilizam são sérios e que, os outros $80 \%$ a utilizam por modismo.

$\mathrm{Na}$ categoria "outros", um entrevistado respondeu que a GC não existe e que a terminologia não foi adequada. Afirma que existe a passagem para uma nova sociedade - refletida nas ocupações, na sustentabilidade, em um mundo novo e na transformação sistêmica do mundo acadêmico. Acrescenta que o sistema acadêmico posto não ajuda, gera fragmentação social na escola.

A questão envolvendo a consolidação da temática é polêmica. As respostas das entrevistas apontam que uma unanimidade, acreditando que a GC não seja um modismo. Segundo alguns entrevistados, evidências apontadas como a contribuição de artigos científicos e congressos na área, revistas com números inteiros dedicados ao tema e universidades evoluindo em suas linhas de pesquisa, nessa direção, são notadamente fatos que ajudam a consolidar a temática. Souza, Alvarenga Neto e Mendes (2007) intitulam essas evidências como "garantias literárias e fenômenos sociais".

No entanto, alguns autores ainda criticam fortemente a GC. Wilson (2006) recentemente reafirmou essa posição, inicialmente apontada em 2002, quando concluiu que a GC seria em grande parte um modismo administrativo, promovido por empresas de consultoria e que provavelmente desapareceria, como modismos anteriores (WILSON, 2002). O autor observa que a retração das consultorias e o desenvolvimento da literatura da área, que não corresponde às expectativas, confirmam tal visão (WILSON, 2006).

Assim, pode-se afirmar que os resultados apontados pelas entrevistas são confirmados pelas garantias literárias existentes e pelos marcos representativos da sociedade brasileira, apresentados no referencial teórico deste trabalho.

\subsection{Temas menos consolidados}

Esta seção trata dos temas que podem ser considerados menos consolidados, divergentes, a partir dos resultados desta pesquisa e em comparação com o que a literatura aponta sobre eles. As análises dos resultados encontram-se segmentadas entre seis e oito categorias diferentes. São elas: conceituação, avanços práticos e teóricos recentes e tendências. 


\subsubsection{Conceituação}

A questão 1 - Conceitue com suas próprias palavras, o que vem a ser GC. - teve como objetivo identificar as diferentes percepções sobre o conceito.

Os resultados da entrevista apontam oito diferentes categorias: "foco na sociedade"; "foco no ciclo do conhecimento"; "foco na organização"; "foco no contexto capacitante"; "foco na inovação"; "foco na gestão"; "foco no fator de produção"; e "outros". Os focos na sociedade, no ciclo do conhecimento e na organização, apresentaram 5 respostas, equivalendo a $17 \%$ cada, seguido do foco no contexto capacitante com 4 respostas (13\%). Os demais focos com 3 respostas cada $(10 \%)$ e outros com $(7 \%)$, com 2 respostas.

o "foco na sociedade" é o mais amplo. Tem a ver com a transformação da sociedade, com a geração do conhecimento e sua colocação no mercado, visando à sua utilização em benefício da sociedade. Envolve a divulgação, o compartilhamento, a democratização do saber e a oportunidade que cada um tem de se manifestar. O "foco no ciclo do conhecimento" considera a gestão do ciclo do conhecimento, suas sete dimensões e a estruturação dos fluxos da informação. O "foco na organização", segundo os entrevistados, trata das bases para os processos da organização, do alinhamento junto aos objetivos estratégicos e da melhoria dos processos em busca da excelência organizacional.

O "foco no contexto capacitante" trata do gerenciamento do contexto e da prontidão. É o espaço onde o conhecimento se manifesta. O conceito de contexto capacitante foi inicialmente proposto por Von Krogh, Ichijo e Nonaka, em 2001, quando defendiam que a criação do conhecimento organizacional é a ampliação do conhecimento criado pelos indivíduos, se satisfeitas as condições contextuais que devem ser promovidas e fomentadas pela organização. Para estes autores (NONAKA, 2007; VON KROGH; ICHIJO; NONAKA, 2001), a criação do conhecimento organizacional depende de fatores como intenção ou visão holística do conhecimento organizacional, cultura e comportamento organizacionais, caos criativo, redundância, variedade de requisitos, mobilização dos ativistas do conhecimento, autonomia e delegação de poderes, além de questionamentos acerca da estrutura organizacional, layout, hierarquia, entre outros (ALVARENGA NETO, BARBOSA, PEREIRA, 2007).

O "foco na inovação" significa criar novas soluções dentro da organização, por meio da inovação. Trata o processo do conhecimento dentro da organização para gerar valor e inclui um conjunto de ações para promover benefícios e possibilitar mudança estratégica. O "foco na gestão" diz respeito à maneira de gerenciar a empresa que tem um foco em conhecimento estratégico como forma de prática de gestão, da capacidade da empresa se manter competitiva e ter cada vez mais grau de competitividade. É gestão mesmo, prática de gestão com foco no 
conhecimento. O "foco no fator de produção" trata o conhecimento como recurso necessário para se fazer alguma coisa, como principal fator de produção, considerando que se vive na sociedade do conhecimento.

Os resultados demonstram uma dispersão em relação ao conceito. Não há consenso entre as respostas, porém há uma complementaridade entre elas.

Em relação à conceituação, o que é citado por muitos entrevistados e ratificado pela literatura é que a terminologia (GC) é insuficiente em seu significado. Alguns entrevistados alegam que essa questão tem sido muito discutida e que poderia ser nominada de outra forma, como gestão de empresas na era do conhecimento ou gestão do conhecimento organizacional, o que, além de incorporar o conceito, consideraria a importância do conhecimento.

Assim, pode-se concluir que, no tocante à questão terminológica, não há consenso na literatura, considerando a amplitude das abordagens tratadas e os efetivos usos que se fazem do conhecimento. Portanto, os resultados apontados pelas entrevistas, que demonstram uma grande dispersão em relação à terminologia, com oito categorias diferentes, podem ser considerados coerentes com a literatura, uma vez que ratificam e complementam o que tem sido objeto de discussão de autores.

\subsubsection{Avanços práticos e teóricos recentes}

As perguntas 3 - Qual é o mais importante avanço prático recente em GC no Brasil ou no mundo? - e 4 -Qual é o mais importante avanço teórico recente em GC? - tiveram como objetivo identificar os avanços práticos e teóricos na área. As respostas foram agrupadas pelo fato de serem muito próximas, permitindo visualizar, na análise, uma comparação entre os avanços práticos e teóricos.

A pergunta relativa aos avanços práticos recentes apontou seis categorias: "importância da temática GC"; "foco no produto/tecnologia"; "valorização dos ativos intangíveis"; "foco nas práticas"; "integração de pessoas e conteúdo"; e "outros". Quanto à frequência, a categoria "importância da temática GC" foi a mais citada, com 26,7\% das respostas, seguida da categoria "foco no produto/ tecnologia" com 20\%. "Valorização dos ativos intangíveis" e "foco nas práticas" apontaram 16,7\% cada e "integração de pessoas e conteúdo" apontaram 13,3\% das respostas dos entrevistados. A categoria "outros" apontou 6,7\% das respostas.

A categoria mais citada (importância da temática) destaca a conscientização para a importância da temática e a adoção da GC em grandes corporações, com o alto nível gerencial da empresa já conhecendo o assunto. Alguns entrevistados citaram que o fato de ter sido criada no governo uma área de GC, tem despertado, nesse âmbito, uma curiosidade razoável em torno dessa questão.

Na categoria "foco no produto/ tecnologia", os entrevistados citaram como maior avanço prático o barateamento dos computadores, a simplificação dos softwares, bem como o fato de grandes empresas de 
tecnologia estarem apostando em sistemas de GC. Como produtos, apontam o desenvolvimento de softwares, sistemas de informação e Gestão Eletrônica de Documentos (GED).

Em "valorização dos ativos intangíveis:, apontam para o reconhecimento dos fatores ligados ao capital intelectual e àqueles que são determinantes no aumento de valor das empresas. Foi citado o caso BNDES, onde percebeu-se a existência desses fatores decisivos para o sucesso da empresa e não descritos no balanço contábil, tais como governança, rede de relacionamentos, capacidade de inovação, pesquisa e desenvolvimento, capacidade de formulação e implementação estratégica.

$\mathrm{Na}$ categoria "foco nas práticas", foram apontados como avanços recentes a gestão de narrativas (storytelling), a construção de redes sociais e interorganizacionais, as comunidades de prática por tema, a gestão por projetos, a capacitação dos gestores, a gestão de competências, a gestão por processos e a certificação por qualidade.

Em "integração de pessoas e conteúdo", os entrevistados citaram o desenvolvimento de uma cultura de integração de informações, desde a coleta ao uso, da forma mais eficaz possível; a criação de um portal corporativo, que consiga integrar pessoas para participar, interagir e compartilhar conhecimento (comunidades de prática); um chat para comunicação; e um local onde estivessem todos os documentos, um ambiente virtual de trabalho. Na categoria "outros", alguns entrevistados disseram que não houve avanço prático, uma vez que as empresas estão muito querendo saber para o que serve a GC e o que ganham com ela. Afirmam que houve apenas o avanço de um entendimento melhor. Citaram, também, a multidisciplinaridade das áreas e a aproximação da GC com a Ciência da Informação.

Quanto aos avanços teóricos, a categorização ficou um pouco mais extensa, com sete categorias: "muito avanço teórico"; "nenhum avanço teórico"; "foco nas práticas"; "foco nas pessoas"; "ativos intangíveis"; "não responderam"; e "outros". A categoria mais citada foi "muito avanço teórico", com 40\% (12 respostas); seguida de "foco nas práticas" com $16,7 \%$. As categorias "ativos intangíveis", "nenhum avanço teórico" e "não responderam" empataram com o mesmo percentual, 10\% cada (três respostas). As categorias "foco nas pessoas" e "outros" foram as que menos apresentaram respostas, com 6,7\% cada (duas respostas).

Interessante abordar que na categoria "muito avanço teórico", metade dos entrevistados citou autores expressivos na área como Thomas Davenport (1998), pela visão mais progressista que os outros; Choo (2003), com as organizações de conhecimento; Castells (1999), com estudo das redes; Nonaka (1998), com a discussão do "BA"; Davenport e Cronin (2000), em artigo que ajudou a organizar a área. Mas, foi Dave Snowden (2002) o mais citado entre os entrevistados (3 citações), com a abordagem da divisão da GC em eras.

Ainda nessa categoria, os entrevistados apontaram que, embora tenha havido muito avanço teórico na área, ele encontra-se disperso e que é necessário saber onde está o avanço teórico consistente. 
Importante ressaltar a contribuição de artigos científicos e congressos na área, revistas próprias de GC com números inteiros dedicados ao tema e universidades evoluindo as linhas de pesquisa nessa direção; são, notadamente, fatos que ajudam a consolidar a temática.

Enquanto $40 \%$ afirmaram que houve muito avanço teórico, outros $10 \%$ acreditam que não houve avanço teórico algum, que a área se encontra paralisada. Na categoria "foco nas pessoas", surgiram abordagens e falas interessantes que valorizaram as pessoas como o fator mais importante do processo de GC.

A segunda categoria mais citada foi "foco nas práticas". Foram abordadas ferramentas e práticas com foco no compartilhamento, como a Internet, comunidades virtuais e, ainda, a gestão do contexto, como ferramentas da construção coletiva do saber.

Em relação aos ativos intangíveis, percebeu-se o mesmo significado descrito nas respostas da pergunta anterior (pergunta 3). Foram categorizados tanto como avanço prático (16,7\%), quanto teórico $(10 \%)$, da mesma forma que foco nas práticas também figurou como respostas a ambas as perguntas, 3 e 4 .

Importante ressaltar que a dispersão nas respostas ocorre em razão da subjetividade do tema, uma vez que reflete uma opinião e ilustra a vivência de cada pessoa com a GC. Isto justifica a multiplicidade de respostas às perguntas.

Pesquisa semelhante foi realizada com 45 especialistas de todas as partes do mundo, utilizando o método Delphi e analisado por meio de frequências, média e desvio padrão (SCHOLL et al., 2004). Aquela pesquisa apontou como o mais importante avanço prático a priorização aos fatores humanos, ênfases em aspectos sociais e humanos, incluindo técnicas de transferência de conhecimento, como a gestão de narrativas (storytelling), comunidades de práticas, seguidas de categorias como sensibilização, gestão de recursos humanos, sistemas tecnológicos, incluindo-se portais, intranet, Internet e ferramentas de criação colaborativa.

Os resultados das entrevistas apontaram categorias de análise semelhantes, porém com graus de importância diferentes. Os resultados apontados na pesquisa acima não descartam, invalidam ou minimizam essas descobertas, mas sim as complementam. Na comparação entre a pesquisa citada e as respostas das entrevistas devem ser consideradas as diferentes categorias em que as respostas foram classificadas, bem como a utilização de métodos de análise distintos (método Delphi e análise de conteúdo).

\subsubsection{Tendências}

A pergunta 8 - Que tendências e futuro você vis/umbra para a GC? teve como objetivo identificar tendências e visões prospectivas da disciplina. 
As respostas foram agrupadas em sete categorias: integração, visão sistêmica e redes; fase inicial; fase terminal; foco no social; foco na inovação; foco nas pessoas; e outros. A categoria que teve mais respostas foi integração, visão sistêmica e redes com $26,7 \%$, seguida da categoria outros com $23,3 \%$. A categoria fase inicial apontou $13,3 \%$ das respostas e as categorias fase terminal, foco no social e foco na inovação $10 \%$ cada. A categoria foco nas pessoas obteve $6,7 \%$ das respostas.

Uma segmentação temporal facilitou o entendimento e permitiu a criação de duas categorias: a fase inicial e terminal. A fase inicial afirma que a GC está muito no começo, que vai evoluir nos próximos cinco anos por força de necessidade, mas é necessário um amadurecimento das pessoas e das empresas. No entanto, a fase terminal contradiz a inicial, afirmando que a GC vai morrer porque estará incorporada nas empresas, como uma área independente nas empresas, vinculada à alta administração, que vai ser consolidada, mas não formalizada quanto à qualidade.

$\mathrm{Na}$ categoria "foco no social", foi identificado o conhecimento e inovação a favor da sustentabilidade e a integração da GC junto à ética e à moral, para fazer a retomada do desenvolvimento do Brasil. Em "foco na inovação", associaram as tendências da GC com fatores ligados à inovação. Afirmaram que essa associação tem vida longa, mas é necessária outra forma de ver essas relações, as condições capacitantes. $\mathrm{Na}$ categoria "foco nas pessoas", disseram que é necessário um destaque para as pessoas e que as ferramentas devem estar em segundo plano.

$\mathrm{Na}$ categoria "outros", inserem-se todas as afirmativas que não foram possíveis de se encaixar nas demais categorias, porém consideradas igualmente importantes para um estudo de tendências. As abordagens foram na gestão de contexto e gestão de narrativas, na avaliação de ativos intangíveis, na ampliação da capacidade de discernir a informação, investindo em técnicas de como efetuar filtros e, ainda, na presença da GC em questões de concursos públicos, em cursos presentes em instituições de ponta e pelo fato de fazerem parte dos planos estratégicos das organizações.

As entrevistas resultantes desta pesquisa apontaram uma multiplicidade de tendências. Embora as opiniões estejam categorizadas separadamente, elas se complementam. As respostas não foram respondidas isoladamente e sim dentro de um contexto, interpretadas e relacionadas à integração, à visão sistêmica e às redes. As respostas mais citadas foram as que envolveram ações relativas ao coletivo. Outro ponto citado foi a visão integrada, a forma interdisciplinar, holística, como se vê a GC, visível pelas lentes de outras ciências como a Antropologia.

Os resultados apontaram uma segmentação temporal para a GC, uma fase inicial e uma terminal. A inicial aponta que é uma área muito nova, em fase de consolidação. A fase terminal afirma que a GC será incorporada em outras áreas maiores (KAY, s.d.), consolidada, mas não formalizada. Souza, Alvarenga Neto e Mendes (2007) apontam que isso pode acontecer, pois caso não haja um fechamento conceitual e a 
formalização do campo, os conceitos e recomendações da GC serão incorporados ao senso comum empresarial, misturando-se às ciências de gestão tradicional.

Outras afirmações dos entrevistados justificam a GC para a inovação, no reconhecimento do conhecimento como fator de produção e, em um entendimento mais amplo, na utilização do conhecimento em prol da sociedade. Apontam também uma mudança no foco, valorizando as pessoas e colocando-as no centro do processo, não apenas fazendo parte do processo, mas como sendo a própria GC (HASSELL, 2007, p.193).

As práticas foram citadas ao longo das respostas, mas não chegaram a criar uma categoria separada. Dentre as práticas, foram citadas a gestão das narrativas e do contexto, análise de redes sociais e uma aposta em imagens e vídeos, tudo com foco na interação entre as pessoas. Como práticas, a pesquisa de Scholl et al. (2004) apontou comunidades de práticas, narrativas e promoção da memória organizacional, com o comprometimento dos fatores humanos e com o apoio de uma cultura propícia à GC.

Como se pode perceber, os resultados apontados nas entrevistas quanto às tendências da GC foram confirmados pela revisão da literatura na área, guardadas as devidas diferenças por conta de abordagens metodológicas distintas.

A próxima seção apresenta as considerações finais.

\section{Considerações finais}

$\mathrm{Na}$ análise dos resultados, verificou-se a existência de duas abordagens distintas dos temas considerados no objetivo da presente pesquisa. Há uma abordagem por temas mais consolidados e convergentes, em que se encontram as discussões referentes à disseminação do tema, barreiras e dificuldades, medição de resultados e modismo. Outra abordagem compreende temas menos consolidados, em discussão efervescente, divergentes e sem consenso, como a questão terminológica, os avanços práticos e teóricos e as tendências.

Embora os temas tenham sido apresentados em dois conjuntos, 0 fato de terem sido classificados como mais ou menos consolidados, não significa que algum deles não mereça ser discutido ou investigado mais minuciosamente. Muito pelo contrário. Pode-se afirmar a partir dos resultados da presente pesquisa que eles precisam de investigações específicas e aprofundadas.

Conclui-se que não houve um consenso nas respostas relativas às tendências, embora elas se complementem e não inviabilizem as demais. A integração, a visão sistêmica e as redes ocupam lugar de destaque no pensamento de especialistas em GC no Brasil.

É possível concluir que há muito que fazer e discutir em torno da GC no Brasil. Enquanto a conceituação da área estiver difusa e sem convergência - o que pode ser observado, nesta pesquisa, como a questão mais inconsistente - a disseminação do termo será prejudicada e a adoção 
da GC nas empresas dificultada, uma vez que estes resultados se complementam e se ajudam mutuamente. Pode-se afirmar que GC é uma área permeada pela complexidade, dadas as inúmeras inter-relações que possui com outras áreas do conhecimento, pela amplitude delas e, ainda, pela incerteza, posto que os homens podem mudar quaisquer tendências.

A GC deve ser pensada para tornar as pessoas mais inteligentes, mais criativas, mais aproveitadas intelectualmente e mais felizes. É a reunião de pessoas, em melhores condições, que fará com que se mudem os paradigmas, que se aproveite o que de melhor a GC pode proporcionar.

Como sugestão, para futuras pesquisas em GC, podem-se apontar a avaliação e a definição de indicadores, por práticas de retenção de conhecimento e por utilização de conhecimento. Outra linha de pesquisa interessante é buscar o melhor entendimento de qual é a motivação que levam as pessoas em compartilhar, o que motiva umas pessoas a compartilhar tanto e outras nada, para que se possa tentar aplicar os resultados com outras pessoas. Questões terminológicas e conceituais também são temas bastante polêmicos e precisam ser mais estudados, na tentativa de consolidar a área. Sugere-se ainda uma discussão mais aprofundada para saber se há ou não uma "versão tropical" da GC, dado o nosso contexto cultural.

Uma ampla disseminação da temática em diversos segmentos da sociedade também se faz necessária, uma vez que os resultados desta pesquisa apontam para um baixo percentual de pessoas informadas sobre o tema.

Uma das limitações do presente trabalho foi o fato de não ter sido possível entrevistar profissionais de todas as regiões do Brasil, a exemplo do Norte e Nordeste, pela dificuldade de deslocamento dos autores, bem como o número de especialistas entrevistados.

\section{Referências}

ALAVI, M.; LEIDNER, D. E. Review: knowledge management and knowledge management systems: conceptual foundations and research issues. MIS Quarterly, v. 25, n. 1, p. 107-136, 2001.

ALVARENGA NETO, R. C. D.; BARBOSA, R. R.; PEREIRA, H. J. Gestão do conhecimento ou gestão de organizações da era do conhecimento: um ensaio teórico-prático a partir de intervenções na realidade brasileira. Perspectivas em Ciência da Informação, Belo Horizonte, v. 12, n. 1, p. 524, jan./abr. 2007.

AN ILLUSTRATED GUIDE TO KNOWLEDGE MANAGEMENT. Disponível em: $<$ http://www.wm-

forum.org/files/Handbuch/An Illustrated Guide to Knowledge Managem ent.pdf>. Acesso em: 02 jan. 2008.

ARAÚJO, V. H. O futuro da gestão do conhecimento: algumas reflexões. In: KM RIO DE JANEIRO, 2006. Rio de Janeiro, 2006. Slides de apresentação. 
BARDIN, L. Análise do conteúdo. Lisboa: Edições 70, 2004.

BARRADAS, J. S.; CAMPOS FILHO, L. A. N. Gestão do conhecimento: a produção científica em periódicos brasileiros entre 1997 e 2006. Informação e Sociedade: Estudos, João Pessoa, v. 18, n. 1, p. 183-194, jan./abr. 2008.

BRUNO, G. D. Maturidade em Gestão do Conhecimento: um estudo sobre o setor elétrico. 2008. 90 f. Dissertação (Mestrado Profissionalizante em Administração) - IBMEC RJ, Rio de Janeiro, 2008.

CAMPOS, L. F. B. Análise da nova gestão do conhecimento: perspectivas para abordagens críticas. Perspectivas em Ciência da Informação, Belo Horizonte, v. 12, n. 1, p. 104-122, jan./abr. 2007.

CASTELLS, M. A sociedade em rede. 5 ed. São Paulo: Paz e Terra, 1999. v.1.

CHOO, C. W. A organização do conhecimento: como as organizações usam a informação para criar significado, construir conhecimento e tomar decisões. São Paulo: Senac, 2003.

DAVENPORT, T. H.; PRUSAK, L. Conhecimento empresarial: como as organizações gerenciam seu capital intelectual. 10 ed. Rio de Janeiro: Elsevier, 1998.

DAVENPORT, E.; CRONIN, B. Knowledge management: semantic drift or conceptual $2000 . \quad$ Disponível em: $<$ http://www.alise.org/conferences/conf00 Davenport-

Cronin paper.htm>. Acesso em: 22 maio 2007.

FINGERL, E. R. Estudos e criação de metodologias voltadas para o intangível. Economia criativa: um caminho de desenvolvimento para o país através da moda e do design. São Paulo: IN-MOD, jun. 2007. p. 2223.

McELROY, M. W. The second generation of KM. Knowledge Management, p. 86-88, out. 1999.

FIRESTONE, J. M.; McELROY, M. The new knowledge management. p.1216, jun. 2003. Disponível em: <http://www.kmci.org/media/New_Knowledge_Management.pdf $>$. Acesso em: 02 jan. 2008.

FRESNEDA, P. S. V; GONÇALVES, S. M. G. A experiência brasileira na formulação de uma proposta de política de gestão do conhecimento para a administração pública federal. Brasília, DF: Câmara dos Deputados, 2007. $83 \mathrm{p}$.

FRESNEDA, P. S. V.; GONÇALVES, S. M. G. A experiência brasileira na formulação de uma proposta de política de gestão do conhecimento para a 
administração pública federal. Brasília, DF: Câmara dos Deputados, 2007. $83 \mathrm{p}$.

GOLDMAN, F. L. Leilões da transmissão da energia elétrica no Brasil de 1999 a 2006: uma avaliação do aprendizado organizacional de $2^{a}$ ordem. 2008. 210 f. Dissertação (Mestrado em Engenharia de Produção) Universidade Federal Fluminense, Rio de Janeiro, 2008.

HASSELL, L. A continental philosophy perspective on knowledge management. Info Systems Journal, v. 17, p. 185-195, 2007.

HENRIQUE, L. C. J.; BARBOSA, R. R. Gestão da informação e do conhecimento organizacionais: em busca de uma heurística adaptada à cultura brasileira. Perspectivas em Ciência da Informação, Belo Horizonte, v.10, n.1, p.4-17, jan./ jun. 2005.

KAY, Alan S. The curious success of knowledge management. In: HANDBOOK OF KNOWLEDGE MANAGEMENT 2: Knowledge directions. [s.d.]. cap. 5, p. 679-87. Disponível em: <http://www.uky.edu/BusinessEconomics/dssakba/Handbook\%20of\%20K M.htm> Acesso em: 20 jan. 2008.

KAPLAN, R. S.; NORTON, D. P. A estratégia em ação: balanced scorecard. São Paulo: Campus, 1997.

MA, Z.; YU, K. Research paradigms of contemporary knowledge management studies: 1998-2007. Journal of Knowledge Management, v. 14, n. 2, p. 175-189, 2010.

MINAYO, M. C. S. O desafio do conhecimento: pesquisa qualitativa em saúde. 9 ed. revista e aprimorada. São Paulo: Hucitec, 2006. 406 p.

NONAKA, I.; KONNO, N. The concepto of "Ba": building a foundation for knowledge creation. California Management Review, v. 40, n. 3, p. 40-54, spring 1998.

NONAKA, I.; TAKEUCHI, H. Criação de conhecimento na empresa: como as empresas japonesas geram a dinâmica da inovação. 9. ed. Rio de Janeiro: Campus, 1997.

PAULK, M.; WEBER, C.; CURTIS, B.; CHRISSIS, M. The capability maturity model: guidelines for improving the software process. Boston: AddisonWesley, 1995 apud CARVALHO, R. B.; FERREIRA, M. A. T.; KILIMNIK, Z. A Gestão por competências como precursora da gestão do conhecimento: survey em médias e grandes organizações. In: ENCONTRO DA ASSOCIAÇÃO NACIONAL DE PÓS-GRADUAÇÃO E PESQUISA EM ADMINISTRAÇÃO - EnANPAD, 31., 2007, Rio de Janeiro. Anais... Rio de Janeiro: ANPAD, 2007.

SCHOLL, W. et al. The future of knowledge management. Journal of Knowledge Management, v. 8, n. 2, p.19-35, 2004.

SHARIQ, S. Z. Knowledge management: an emerging discipline. The Journal of Knowledge Management, v. 1, n. 1, set. 1997. 
SIMÃO, S. H. R.. Gestão do Conhecimento nas Instituições Educacionais. [2008]. Disponível em: $<$ http://lantec.fae.unicamp.br/lantec/pt/tvdi portugues/sylvia.pdf $>$. Acesso em: 15 set 2010.

SNOWDEN, D. A nova forma de ser simples: a gestão do conhecimento. HSM Management, São Paulo, v. 4, n. 39, p. 98-107, jul./ago. 2003.

- Complexes acts of knowing: paradox and descriptive selfawareness. Bulletin of the American Society for Information Science \& Technology, v. 29, n .4, p. 23-28, abr./maio 2003.

SOUZA, R. R.; ALVARENGA NETO, R. C. D.; MENDES, K. C. I. Mapeamento semântico através da análise de ocorrência de descritores sobre gestão do conhecimento. Transinformação, Campinas, v. 19, n. 1, p. 19-30, jan./ abr. 2007.

STEWART, T. A. Capital intelectual: a nova vantagem competitiva das empresas. 2 ed. Rio de Janeiro: Campus, 1998. 237p.

STUDER, R.; BENJAMINS, V. R.; FENSEL, D. Knowledge engineering: principles and methods. Data and Knowledge Engineering, v. 25, p. 161197, 1998.

SVEIBY, K. What is knowledge management? abr. 2001 Disponível em: $<$ http://sveiby.konverge.com/articles/KMInitatives>. Acesso em: 23 out. 07

TEIXEIRA FILHO, J. Gerenciando conhecimento: como a empresa pode usar a memória organizacional e a inteligência competitiva no desenvolvimento de negócios. Rio de Janeiro: Senac, 2000. 192 p.

TOFFLER, A.; TOFFLER, H. Riqueza revolucionária: o significado da riqueza no futuro. São Paulo: Futura, 2007. 591 p.

VON KROGH, G.; ICHIJO, K.; NONAKA, I. Facilitando a criação de conhecimento: Reinventando a empresa com o poder de inovação contínua. Rio de Janeiro: Campus, 2001.

WILSON, T. D. A problemática da gestão do conhecimento. In: TARAPANOFF, K. (Org.). Inteligência, informação e conhecimento. Brasília, DF: IBICT, UNESCO, 2006. p.37-55.

WILSON, T. D. The nonsense of 'knowledge management'. Information Research, v. 8, n. 1, 2002. Disponível em: <http://InformationR.net/ir/81/paper144.html>. Acesso em: 20 jan. 2008. 